Supporting information for

\title{
Counteranion Dependent Protonation and Aggregation of Tetrakis(4-sulfonatophenyl)porphyrin in Organic Solvents
}

Giovanna De Luca, Andrea Romeo and Luigi Monsù Scolaro* 


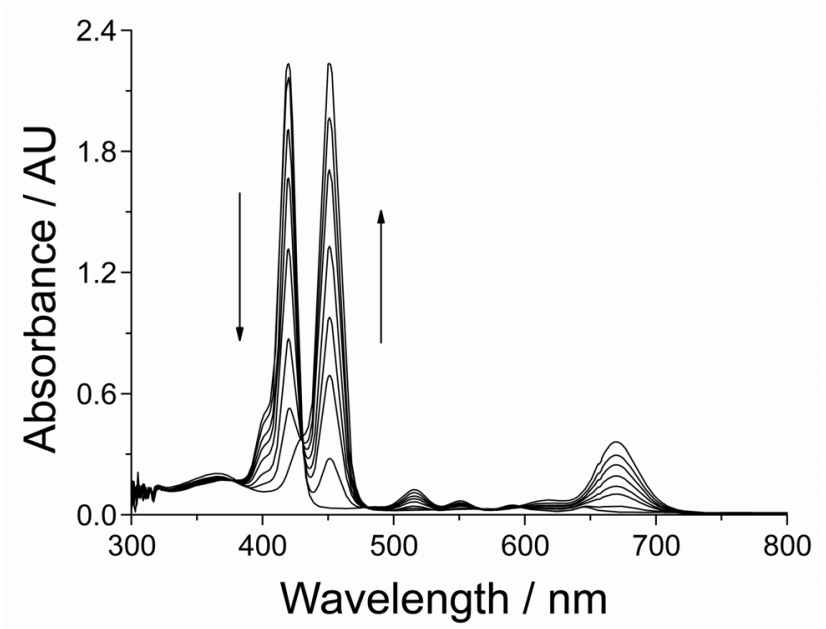

Figure S1. UV/Vis spectral changes following the stepwise addition of $\mathrm{HCl}$ to a dichloromethane solution of $(\mathrm{TBA})_{4} \mathrm{TPPS}$, in the presence of a TBACl excess. The arrows mark the increase of acid concentration. ([porphyrin] $=3.7 \mu \mathrm{M},[\mathrm{TBACl}]=0.05 \mathrm{M}$, [HCl] up to $200 \mu \mathrm{M}$ ).

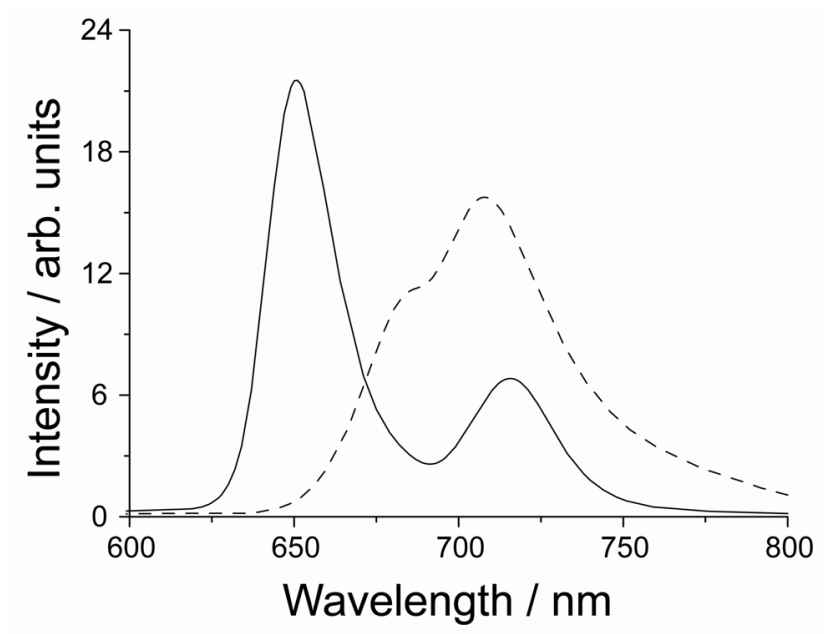

Figure S2. Fluorescence emission spectra before (solid line) and after (dashed line) the additions of $\mathrm{HCl}$ to a dichloromethane solution of (TBA) $)_{4}$ TPPS, in the presence of a TBACl excess. $([$ porphyrin] $=3.7$ $\mu \mathrm{M},[\mathrm{TBACl}]=0.05 \mathrm{M},[\mathrm{HCl}]=200 \mu \mathrm{M})$. 


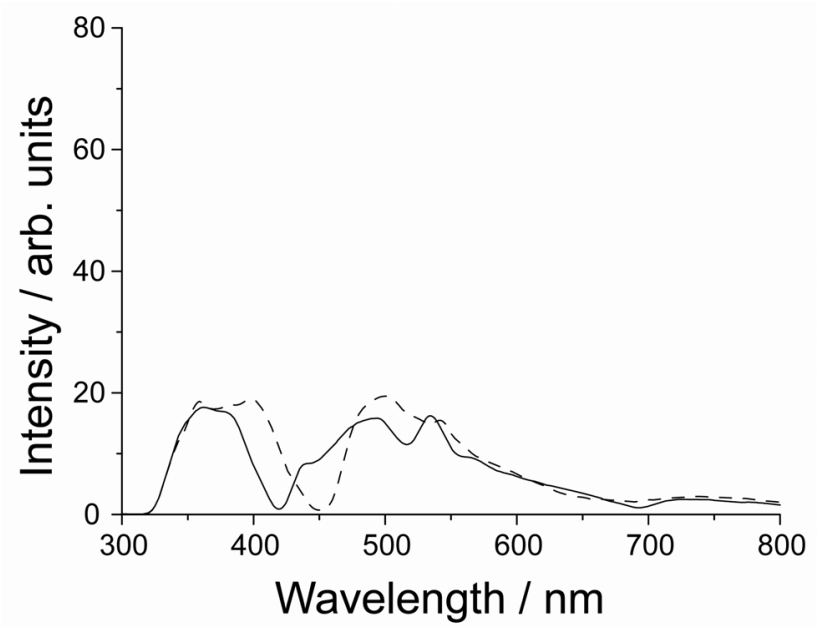

Figure S3. RLS spectra before (solid line) and after (dashed line) the additions of $\mathrm{HCl}$ to a dichloromethane solution of $(\mathrm{TBA})_{4} \mathrm{TPPS}$, in the presence of a TBACl excess. ([porphyrin] $=3.7 \mu \mathrm{M}$, $[\mathrm{TBACl}]=0.05 \mathrm{M},[\mathrm{HCl}]=200 \mu \mathrm{M})$. 